\title{
Developing Language Skills in Preschool Children through Games
}

\author{
Shpëtim Zymberaj \\ University “Ukshin Hoti” Prizren
}

\begin{abstract}
Preschool institution as a first level of the unified system of education bases its activity on the "student centered" philosophy of education which promotes different ideas from that of traditional education. Through organized activities in all its field activities foreseen in a curricula, the preschool institution with its structured environment in harmony with the goals and concrete objectives offers numerous possibilities to develop general abilities of children, which create appropriate conditions to prepare and offer optimal readiness to master the reading and writing skills. The activities that we handle and which aim accomplishment of this concrete objective come out and are supported by the living context of children in accordance to fulfillment and urging of the knowing interests for developing and deepening the knowledge of letters, sounds, reading and writing. In this view, children should not be imposed or prevent the interest they show in order to learn letters, sounds, reading and writing. Working with children of this age in order to understand and learn letters isn't a program-based obligation because this is the school's duty and not the preschool institution's obligation. Obligations cause unwanted consequences which generate different psych-neurotic disorders. Overwork and heavy workload of these children, diminishes or misplaces children's trust on possibilities of overcoming difficulties in learning basic letters, sounds, reading and writing. In addition, it diminishes and misplaces their interest in continuing school and the learning process. Therefore in order to prevent these negative consequences, there is an immediate need for a general preparation which offers children a possibility to transfer and generate skills in specific fields and content. The best strategy to prepare children to recognize letters, sounds and master reading and writing is no doubt activity through games which in this case represents the main substance for organizing activities in aspects of integrated education within preschool institutions.
\end{abstract}

Keywords: language, words, sounds, letters, game, fun

\section{Introduction}

Preschool education requires a great commitment in continuity because it represents the first level of pre-university education in our country. "If a child has passed the pre-school education, integration into elementary school becomes easier." ${ }^{1}$ Thus, quality education in the early childhood has a high selection in the entire mandatory education system and for all people who benefit from this education. The basic literature that is intended for preschool education has clarified the areas of development, the curriculum lines to be followed, the objectives its aims to achieve, and the materials to be used during the educational activities. Different educational models are implemented in the preschool education institutions of our country, such as traditional education "Step by Step", Rexhio-Emilia, "Montesor", "Frobel " etc. ${ }^{2}$

Achieving success with pre-school children requires an interactive methodology, an instructive and active educational process, updated with sophisticated methods, strategies and advanced learning techniques. Therefore, it is the responsibility of each educator/teacher to make effective use of multiplicity of strategies and methods of education in order to achieve the objectives set, and in this way the children can directly see their progress and their results. As a matter of fact, preschool educators need more in-depth theoretical and practical knowledge of the new methods that are in use, so that the work with children will also be more productive. Responsive educators do not hesitate, but they consistently associate the methods of education with working techniques that help achieve the objectives set out in the curriculum. Every passionate educator should strive to discover the children's learning style and preferences and adapt the materials and activities in that way. ${ }^{3}$ 
Children prefer styles such as: learning by discovering; learning by repeating things mechanically; learning by demonstrations or examples; learning by asking; etc.

Children interact with each other, thus learning is the result of this interaction with the surrounding environment that includes objects, people, and the surrounding world. The educators are aware that the children who they are working with belong to different age groups and also have different levels of intelligence, but they are all individuals who are able to learn, thus the work needs to be adapted to their primary level (their age group). All work with preschoolers is developed in an external and internal physical environment. There are many factors associated with this environment that help the growth, development, and progress of a child. An location destined for preschoolers should be a quiet place, clean, healthy, and a safe environment for children.

1. National Strategy for Development of Pre-University Education 2004-2015, Tirana, June, 2004.

2. Ermioni Hoxha Cekani, Pre-school Teacher's Book (for Groups I, II and III) Polis Publications, Tirana 2010 pg.10.

3. Work quoted pg. 21.

There should be different games available for children, because it is not said in vain that the game is the work of children.

Kids love games, they design them on their own. While playing with each other they learn and have fun. As such, the game itself is an entertaining activity. When playing various games at the same time, children are fulfilling their need to play spontaneously. The game is not only entertainment and fun for them, but through it children efficiently develop their skills. By playing, they cite the name of the game, sing songs, and recite short strings, in this way they develop language skills. While playing children build different towers and objects, and then they find the right place to place different mosaic figures, etc. Through games, children develop small muscle skills, eg. Playing with mud or cutting with scissors. Kids love the ball as well. Playing with the ball and running, provides them the opportunity to develop big muscle skills. Children have their own imagination. They create their own fairy tales, play with dolls, and even try to dress like someone else, this way they develop creative skills. While playing, children exchange their roles, split in minor groups or even discuess the rules of the game. Likewise, they also talk about the characters and their roles in theatrical "shows". In this way, children develop social skills. Thus, apart from developing different skills, children learn many other things during a game. Playing with their friends, help them build strong and positive relationships with other people. Children are ready to show their contribution during a game because they feel a part of it when they are playing. Through game children not only have fun but they learn new things. Looking from another point of view, knowing the importance of games in the child's development, experts have designed curricula that use the game to promote and develop cognitive development of children but also to teach them reading and writing skills. For example, Bodrovaans of Leongs $(2001,2003)$ have designed the program "Mind Means" a program dedicated to children who attend the kindergarten. The uniqueness of this program is that it attaches particular importance to the application of socio-dramatic games in affirming the ability to read and write, mainly relying on the principles of Vygotski's theory and the work of his student, Elkan. Preschool classes include spaces where, among other things, are reserved to play dramatic games. In this environment children start to get used to their everyday life in kindergarten and respect the rules of the community feeling responsible for the environment they spend their time in. Children play there imitating animals and fairy tales, imitating their voice, body, gestures and facial mimicry. In addittion, wearing costumes, different character masks, they make animations with dolls and various tools, they also learn to differentiate theater equipment, scene, scenery, costumes, lighting, acoustics, and experience drama events. Educators' support the children's games by helping them create imaginary situations, providing them with scenic material and enabling the gaming process to continue.

Children with the support of the educator draw up script scenarios including the theme, roles, and rules on which the game is based. 4

The game is a way through which the child makes a connection with the outside world. Along with active child engagement and satisfaction, one of the most accepted aspects of the game is the aspect of its internal motivation. Children should be motivated to learn, read, and write; therefore through different activities of a game they are motivated and at the same time learn how to form linguistic concepts. The most appropriate strategy for preparing children for recognition, letter separation, reading and writing is undoubtedly the activity through the game. The game in the function of education for the recognition and learning of reading and writing skills creates favorable conditions for a natural preparation of preschool children in accordance with the particular characteristics of the psycho-physical, socio-emotional, and their intellectual development. 
Structured teaching environments in various educational fields create favorable conditions for the development and the education of cognitive interests, skills, and habits at this age. Fields of activities in preschool institutions are numerous such as: language education, physical and health education, mathematics, artistic, self-knowledge and the world around us. Research has shown that children with preschool preparation not only know the letters but also they apply skills in their writing. In the field of language development and communication, educators and parents should work based on some of the following components: developing through symbols, spoken language, heared language, written language, knowledge of books and signs, sounds, letters, as well as learning strategies.

A number of scholars support the idea that the years from zero to six are the most critical period in the development of reading and writing skills of children as well as mathematical skills. Educators should be aware and pay importance to the fact that that during this time children have deal with language, books, and other interactive activities. Today, developed and advanced countries in many facilities of pre-school education have designed special curricula aimed at promoting the ability of pre-school children to read and write.

All of these programs incorporate various activities and games and use different materials that help promote the development of these skills. In his theory, Lev Vygotsky emphasized the role of cultural tools such as language and writing having an important role in a child's development. Converging with the surrounding environment and providing opportunities for children to explore and interact with the environment in the peer society and others, increases the child's development. His conclusion was that children learn through practical experiences.

\section{Trust in Education is Key to the Future, Scientific Bulletin, No.2, November, Tirana, 2010}

Language development experts have identified six literacy skills for children. Rich vocabulary or knowledge of names and things is a very important skill for children as they learn to read and write. Most children start school by recognizing three thousand to five thousand words.

Children enrich their vocabulary when reading books of various kinds and naming things that are around them. ${ }^{5}$

From another point of view, linguistic development in early childhood stage besides creating a rich vocabulary of words that children pronounce should also increase their knowledge in the following four main areas, regardless of the language or dialect they use:

Phonology or sounds, semantics or encoded meanings, syntax or the way in which words are formed and combined, as well as pragmatics or knowledge on the use of the language in different contexts; so language in relation to the user. Educators should continually try to increase children's interest in their enjoyment of the book. They are encouraged to have higher motivation for the books because this is where their indicative skills are developed, hence a child is able to describe the events of his/her birthday party or describe their experiences during the summer holidays. Encouraging the child to show and describe various things he has done in the regular order will be a good opportunity to develop this ability. ${ }^{6}$

Perceptive language and understanding what others say, is gradually developed from the age of six months. However the expressive language and the creation of words takes place soon after the age of one year and continues through a multiple expansion of words about the second half of the second year. This great enrichment of the vocabulary is closely related to the ability of children to repeat the words pronounced and also helps the development of the ability to pronounce. Letter recognition involves learning that letters call sounds, so are sound names. The letter is the basic unit of writing and reading. Recognition of alphabet letters has consistently proved that it is a strong basis for the child's reading level in the future. They differ from each other and each letter designates a certain sound. There is a relationship between letters and sounds of a language. That is, the phonics. When the child is clear that a letter represents a sound and when a group of letters make up the same sound then they are learning the phonics. Learning the phonics helps children to read and write. The written language can be compared to a code. Children will read simple short books that contain the sound or the word they are learning. They must also write a lot to reinforce the connection between the sound and the written word.

Kindergarten educators should be prepared to make this selection: The words spoken are composed of phonemes, and the words written consist of letters. The knowledge of the alphabetic principle emphasizes that the letters in the written words represent the phonemes in the words pronounced.

5.Karaj,Theodor (2005): Child Development Psychology, Progres, Tirana, pg.57 
6.Ermato,Erlehta (1995), Some psychological and social features of the preschool, Tirana, pg.36

Over the time, the child begins to understand the grammatical rules and the combination of words, about the age of two. The acquisition of vocabulary and grammar continues gradually throughout the pre-primary and primary cycle. Around the age of three, the child begins to use complex words and also some special words systems. At about the age of five, the child's linguistic usage is similar to that of an adult. On the other hand, teaching children how to write from an early age is also an important skill. Children begin to realize that writing differs from drawing. Usually children between the ages of four and six begin to write letters and numbers. Preschool and kindergarten children develop reading and writing skills at the same time. This means that one area of development helps the other. The kindergarten teachers should help children learn the script functions. It is important for children to understand that writing is a way to share ideas and knowledge, so it is a method of personal communication and transmits a message that can be read later.

\section{Conclusion}

The game in the function of education for the recognition and learning of reading and writing skills creates favorable conditions for a natural preparation of preschool children in accordance with the particular characteristics of the psychophysical, socio-emotional, and their intellectual development. Structured teaching environments in various educational fields create favorable conditions for the development and the education of cognitive interests, skills, and habits at this age. Fields of activities in preschool institutions are numerous such as: language education, physical and health education, mathematics, scientific, etc. Through various activities in the field of physical and health education, children during various systematic exercises train for coordinated hand and eye movements and even for the entire body. Kindergartens equipped in structured settings in preschool institutions are stimulating places using tools and materials such as paper, plasticine, clay, soft wire, rods, seeds etc. In these environments the children not only experience positive emotions but they also develop and exercise the muscles of their hands and fingers. Children are trained to be aware of motor activities that are developed by time. These psycho-motor skills are developed and strengthened through the organization of functional games, rhythmic exercises, and thematic games. Research has shown that children with preschool preparation not only know the letters but also they apply skills in their writing. In the field of language development and communication, educators and parents should work based on some of the following components: developing through symbols, spoken language, heared language, written language, knowledge of books and language signs, etc.

\section{Literature}

[1] Mato, Erlehta, 1995, Some psychological and social features of the preschool, Tirana. 2.Karaj,Th,2005, Psychology of Child Development Progress, Tirana

[2] Musai,Bardhyl,2003, Methodology of Teaching, Pegi, Tirana

[3] Kincher,J,2005, Psychology for Children, Logos, Skopje

[4] Nikoliq,Stanisha,2005, The World of Child Psychology, Furkan ISM,Skopje 